\title{
Predisposition Factors Analysis for Fournier's Gangrene Defects Closure Complication
}

\author{
Bayu Fasi Bermania, Sitti Rizaliyana ${ }^{a^{*},}$ Ira Handriania \\ aDepartment of Plastic Reconstructive and Aesthetic Surgery, Faculty of Medicine Universitas Airlangga \\ *Corresponding author: Bayu Fasi Bermani - Department of Plastic Reconstructive and Aesthetic Surgery, Faculty of Medicine Universitas \\ Airlangga. Email address: bayufasi@gmail.com
}

\section{ARTICLE INFO}

Keywords:

Fournier's gangrene, Complication, Closing defect

\begin{abstract}
Background: Fournier's gangrene is a rare and rapidly progressive, necrotizing fasciitis affecting the external genitalia and perineum. Based on the case series that have been reported, the incidence rate of this case is $88 \%$ with mortality rate of $20 \%-40 \%$. The study aims to share our policy in managing Fournier's gangrene and identifying risk factors that can affect the outcome of defect closure.

Method: The medical records of 10 patients with Fournier's gangrene who presented at the Dr. Soetomo Hospital Surabaya from January 2017 to December 2018 were reviewed retrospectively. We analyzed characteristics of the patients, risk factors, methods of defect closure, and case outcome. There are 10 Fournier's gangrene patients at Dr. Soetomo Academic General Hospital from January 2017 to December 2018. We analyzed the patient's medical records retrospectively on the patient's characteristics, risk factors, method of closing Fournier's gangrene defects, and the final outcome of the case.

Results: There were ten men enrolled in the study, and the mean age was 49.3 \pm 11.51 years. All patients received broad-spectrum antibiotic therapy, and extensive surgical excision. This study found that diabetes mellitus and uncontrolled patient blood sugar levels, statistically there is no effect on failure of defect closure in Fournier gangrene patients, but clinically, the relative risk value shows that blood glucose levels have a risk factor of 6 times. increasing the incidence of failure to close the Fournier gangrene defect.

Conclusions: Fournier's gangrene is still considered a severe disease with fairly high mortality rate. Early recognition of predisposition factors associated with invasive and aggressive treatment options is very important in efforts to to reduce morbidity.
\end{abstract}

\section{INTRODUCTION}

$\mathrm{F}$ ournier's gangrene is a necrotizing fascia infection that affects the genital and perianal regions, and caused by extensive soft tissue necrosis (Yücel et al., 2017). Fournier's gangrene was first described by Baurrienne in 1967 and Jean Alfred Fournier in 1983 as a broad perineal necrotizing soft tissue infection ${ }^{1}$

Fournier's gangrene is characterized by the progressive spread of necrosis to the skin and subcutaneous tissue along with polymicrobial infections caused by aerobic and anaerobic bacteria. Any trauma in the perineal area or infection in the urinary tract forms the initial focus of the disease. Fournier's gangrene is seen in general in patients with immune disorders such as diabetes, alcoholics, seniors, HIV seropositivity and malnutrition ${ }^{2}$

Symptoms vary from pain in the anorectal or genital area with minimal presentation of symptoms in the form of skin necrosis, necrosis that rapidly spreads to the skin and soft tissue, systemic sepsis without a clear source of infection. Fournier's gangrene 
is a surgical emergency, and because of differences in clinical presentation, patients may initially be encountered in a variety of clinical settings. Delay in diagnosis and treatment of this condition can be fatal, it is very important not to ignore symptoms, even if the symptoms are not specific. After Fournier's gangrene is diagnosed, proper treatment is very important ${ }^{3}$

Fournier's gangrene is relatively rare, but the exact incidence rate of this disease is unknown. The overall incidence of this case is $1.6 \%$ per 100,000 men per year worldwide. The incidence peaked and remained stable after the age of 50 in $3.3 \%$ of cases per 100,000 men. An epidemiological study in the United States mentions the highest incidence in southern America at $1.3 \%$ per 100,000 men ${ }^{4}$

This retrospective study aims to evaluate the predisposing factors of Fournier's gangrene, study the most common microorganisms associated with Fournier's gangrene and to study the results in the management of Fournier's gangrene.

\section{METHODS}

\section{Study Design}

This was an observational study with a retrospective design. Ten medical records patients admitted to the Dr. Soetomo Hospital Surabaya General Surgery Department, with a diagnosis of Fournier's gangrene during the 2year period between from January 2017 to December 2018. The data collected include basic identity data, history taking, physical examination, diagnosis, laboratory examination, treatment, follow-up, and counselling. Ethical clearance was obtained before this research was conducted from the Ethical Committee of Dr. Soetomo General Hospital Surabaya in Desember 2019. Inclusion criteria in this study included patients undergoing wide surgical excision of scrotal and/or perineal necrosis along with other involved areas with a postoperative diagnosis of Fournier's gangrene. Excluded were patients who died during treatment, patients who refused surgery to close the wound and patients who had raw surfaces recovered from the pain. The prognostic variables used in the outcome analysis were the patient's age, female gender, history of diabetes. The independent variables in this study were predisposing factors, age, diabetes mellitus, alcohol exposure, and hypertension, type and number of bacteria.

\section{Statistical Analysis}

The dependent variable in this study is the failure rate and the success of the defect closure in Fournier's gangrene. Statistical analysis was performed using the data that has been obtained from the data collection process will be converted into tables, then the data will be processed using the SPSS (Statistical Package for the Social Sciences) computer program. The statistical test used is a nonparametric statistical test. The correlation of prognostic variables and mortality were studied by univariate analysis using chisquared test and Fisher's exact probability test. Statistically significant variables were entered into multivariate regression analysis using logistic regression. $\mathrm{P}$ values were reported as the result of two-tailed testing and $P$ values less than 0.05 were considered as statistically significant.

\section{RESULT}

Out of 10 patients who were diagnosed as Fournier's gangrene in the period January 1, 2017 - December 31, 2018. Of all patients undergoing hospitalization in the Hospital Inpatient Unit of Dr. Soetomo Surabaya. The study showed that out of 10 patients, all were male and the average age group of 46-55 years was $40 \%$. The mean age of patients in this study was 49.3 years with a standard deviation of 11.51. Correlation between age and defect closure complication was statistically analysis show that no correlation significant with $p$ value 0.276 (table 1 )

There were 2 patients who smoked but none had complications at defect closure. Based on the result of the Fisher exact test found that there was no significant risk factor 
for smoking with complications of defect closure $(p=0.933)$. This study also shows that 3 patients have a history of drinking alcohol and 2 of these patients have complications of closing defects. Based on the relative risk (RR) history of drinking alcohol against complications at closing the defect is 4.67 which means there is an increased risk of complications at closing the defect in patients with a history of drinking alcohol. However, the Fisher exact test results found that the risk factor for a history of drinking alcohol on the presence of defect-closing complications was not significant $(\mathrm{p}=0.116)$, meaning that drinking alcohol history increased the risk of closure complications in the defect but statistically this was not significant. This study also found that diabetes mellitus and uncontrolled patient blood sugar levels, statistically there is no effect on failure of defect closure in Fournier gangrene patients, but clinically, RR value shows that blood glucose levels have a risk factor of 6 times increasing the incidence of failure to close the Fournier gangrene defect. Other risk factors, such as hypertension, the presence of bacteria, did not show a significant effect on the failure of defect closure in Fournier gangrene patients, with a p value $>0.05$ (table 2 )

Table 1 Evaluation of age distribution

\begin{tabular}{ccccc}
\hline Group Age & & n & Mean \pm SD & $\begin{array}{c}\text { P } \\
\text { value }\end{array}$ \\
\hline Complication & + & 3 & $46,57 \pm 0,71$ & \\
& - & 7 & $55,67 \pm 12,86$ & 0,276
\end{tabular}

Note: $\mathrm{SD}=$ Standard Deviasi

Table 2. Distribution of Predispotition Factor analysis for fournier's gangrene defects closure complication

\begin{tabular}{lcccccc}
\hline \multicolumn{1}{c}{$\begin{array}{c}\text { Predispotition } \\
\text { Factor }\end{array}$} & Status & complication & $\begin{array}{c}\text { No } \\
\text { complication }\end{array}$ & Total & $\begin{array}{c}\text { p } \\
\text { value }\end{array}$ & RR \\
\hline Smooking & + & $0(0 \%)$ & $2(100 \%)$ & $2(100 \%)$ & 0,933 & \\
Drink alcohol & - & $3(37,5 \%)$ & $5(62,5 \%)$ & $8(100 \%)$ & & \\
& + & $2(66,6 \%)$ & $1(33,3 \%)$ & $3(100 \%)$ & 0,367 & 4,67 \\
Diabetes Melitus & + & $1(14,2 \%)$ & $6(85,7 \%)$ & $7(100 \%)$ & & \\
& - & $3(37,5 \%)$ & $5(62,5 \%)$ & $8(100 \%)$ & 0,933 & \\
Glucosa level & + & $2(100 \%)$ & $0(0 \%)$ & $2(100 \%)$ & 0,933 & 6 \\
Hipertensi & - & $1(16,6 \%)$ & $5(83,3 \%)$ & $6(100 \%)$ & & \\
& + & $3(37,5 \%)$ & $5(62,5 \%)$ & $8(100 \%)$ & 0,933 & \\
Bacteri Gram Positif & + & $2(22,2 \%)$ & $7(77,7 \%)$ & $9(100 \%)$ & 0,600
\end{tabular}


Rizaliyana: Predisposition Factors Analysis ...

\begin{tabular}{|c|c|c|c|c|c|}
\hline \multirow[t]{2}{*}{ Bacteri Gram negatif } & + & $3(37,5 \%)$ & $5(62,5 \%)$ & $8(100 \%)$ & 0,933 \\
\hline & - & $0(0 \%)$ & $2(100 \%)$ & $2(100 \%)$ & \\
\hline \multirow{2}{*}{$\begin{array}{l}\text { Bacteri Gram Positif } \\
\text { and negatif }\end{array}$} & + & $2(28,5 \%)$ & $5(71, \%)$ & $7(100 \%)$ & 1,00 \\
\hline & & $1(33,3 \%)$ & $2(66,6 \%)$ & $3(100 \%)$ & \\
\hline
\end{tabular}

Note: RR= Relative Risk

The results of the risk ratio of the mixture of gram-positive and negative germs to the presence of complications at defect closure and the Fisher extract results found that there was no significance of a mixture of gram-positive and negative germs on the presence of complications at defect closure ( $p>0.05$ ). This means that the presence of a mixture of gram-positive and gram-negative bacteria is not a proven risk factor for complications in defect closure (table 3 ).

Table 3. Distribution of bacterial status resulting from cultures of Fournier's gangrene with complications at defect closure

\begin{tabular}{lcccc}
\hline & & n & Mean \pm SD & P value \\
\hline \multirow{2}{*}{ Complication } & + & 3 & $2,33 \pm 0,58$ & 0,430 \\
& - & 7 & $1,86 \pm 0,90$ & \\
\hline
\end{tabular}

Note: $\mathrm{SD}=$ Standart Deviasi

\section{DISCUSSION}

As far as can be traced, this is the first study to test the outcomes of Fournier's gangrene patients in the SMF Plastic Reconstructive \& Aesthetic Surgery of RSUD

Dr. Soetomo Surabaya. Research on the outcome of Fournier's gangrene patients in scientific publications is also not widely found. Some surgical reconstruction techniques in Fournier's gangrene are expected to protect the function of the testes by considering their cosmetic functions. There

are no guidelines that mention the best technique between skin graft or flap. The success of closing defects in Fournier's gangrene depends not only on the technique used, but also is influenced by several factors that play a role in the success of closing defects

in Fournier's gangrene. The most studied comorbid factors are diabetes mellitus, history of alcohol, age, the bacteria that causes Fournier's gangrene and others. ${ }^{5}$
This retrospective study examined the factors that exist in patients towards the successful closure of defects in Fournier's gangrene. In this study, various factors such as age, smoking status, alcohol history, diabetes mellitus, hypertension, and bacteria that cause infections to successfully close defects in Fournier's gangrene were investigated.

Research on risk factors conducted by Oymaci (2014) on mortality in Fournier's gangrene, states that there is no statistically significant difference between groups of Fournier's gangrene patients without mortality including failure of reconstructive therapy with groups with mortality. This is due to age not being the cause of failure to close the defect in Fournier's gangrene, but due to other causes ${ }^{3} 6$

The most frequent predisposing factor in the incidence of Fournier's gangrene is diabetes mellitus. Chemotaxis and phagocytosis are the effects caused by 
diabetes mellitus. Oymaci's research (2014) also mentioned that diabetes mellitus had a significant relationship with $\mathrm{p}<0.005$ in the occurrence of complications in surgical therapy in Fournier's gangrene. In this study found that statistically diabetes mellitus did not significantly influence complications in surgical therapy, namely the closure of the defect in Fournier's gangrene.

This study examines, from the research subjects obtained uncontrolled blood sugar state when performing reconstructive closure surgical therapy, statistically has a significant relationship with $\mathrm{p}$ value $<0.05$. These results indicate that a state of high and uncontrolled blood sugar can cause complications such as closure of a failed defect in Fournier's gangrene by flap closure technique.

Another factor that also influences the outcome of Fournier's gangrene patients is a history of drinking alcoholic. 7 Fournier's gangrene is a synergistic infection caused by a combination of aerobic organisms and anaerobic organisms creating a synergy of enzyme production that rapidly increases infection and spreads of staphylococcal bacterial infections in blood clots and interferes with blood carrying oxygen to the surrounding tissue. Anaerobic bacteria produce molecules that trigger chemical reactions (enzymes) that further increase the spread of infection. ${ }^{8}$

The main strength of this study is that this research can be known what factors can statistically influence the success of surgical therapy in Fournier's gangrene, either with skin graft or with a flap. Another strength of this study is the use of software to measure the outcomes of Fournier's gangrene patients in the SMF Plastic Reconstructive \& Aesthetic Surgery RSUD Dr. Soetomo Surabaya so that this kind of research can be carried out observatively retrospectively.

This study still has many weaknesses, the research subjects in this study are not too many, this is because there are very few Fournier's gangrene patients in the 2-year study period. In addition, the retrospective nature of this study limits the prognostic variables that are possible to record accurately at the time of hospitalization. This study is limited by the retrospective design, the inadequacy of some data in the registry and the inability to access all.

\section{CONCLUSION}

Fournier's Gangrene is a rapidly progressive disease which is difficult to take under control and is associated with high mortality and morbidity. Research similar to this will be able to obtain greater data and possibly be used for decision making regarding Fournier's gangrene therapy.

\section{REFERENCES}

1. Karthikeyan G, Kumarasenthil M. A Study on Fournier' s Gangrene. 2017; 4(7): 1519-23.

2. Ahmad I, Maurya RK, Mahmud AA, Pathak B, Maurya SK, Harswarup AL. Medial Thigh Flap : An Eminent Method of Reconstruction of Scrotal Defect Following Fournier 's Gangrene. 2018;

3. Oymacı E, Coşkun A, Yakan S, Erkan N, Uçar AD, Ylldırım M. Evaluation of factors affecting mortality in Fournier ' $s$ Gangrene : Retrospective clinical study of sixteen cases. 2014; 85-9.

4. Sorensen MD, Krieger JN. Fournier 's Gangrene : Epidemiology and Outcomes in the General US Population. 2016; 98195: 249-59.

5. Sparenborg JD, Brems JA, Wood AM, Hwang JJ, Venkatesan K. Fournier' s gangrene : a modern analysis of predictors of outcomes. 2019; 8(4): 374-8.

6. Karian LS, Chung SY, Lee ES. Reconstruction of Defects After Fournier Gangrene : A Systematic Review. 2015; 155-69.

7. Bhatnagar MM. Fournier's gangrene: A review of 110 cases for aetiology, predisposing conditions, microorganisms, and modalities for coverage of necrosed scrotum with bare testes. 2008; (May 2014).

8. Montrief T, Long B, Koyfman A, Auerbach J. Fournier gangrene: A review for emergency clinicians. J Emerg Med [Internet] 2019;(June): 1-13. 